\title{
Fear spreads as number of Ebola cases in Guinea rises
}

\author{
Anne Gulland
}

London

The charity Médecins sans Frontières (MSF) has been forced to withdraw staff from a clinic in Guinea that was treating patients infected with the Ebola virus, after an angry crowd gathered.

The clinic, in the rural area of Macenta, is now being run by the ministry of health after people accused MSF staff of bringing the disease to the town.

Sam Taylor, MSF's emergency coordinator in Guinea, said that the charity's head of mission in the country was negotiating the staff's return.

"The health centre is not shut-patients are still in there and being cared for by ministry of health staff but without the support of the MSF team," he said.

He added that a lot of rumours were circulating among the local population about the spread of the disease, such as the possibility of catching it from sitting next to an infected person.

"This is understandable as it's the first time Guinea has had an outbreak of the disease. There is a lot of concern and fear. Stigmatisation is something we are seeing more of, against patients suspected of having the disease and against family members," said Taylor.

He said that MSF, which has 52 staff in the country, and other agencies such as the ministry of health, the World Health Organization, the International Committee of the Red Cross, and the US Centers for Disease Control and Prevention were working hard to inform people about the spread of the disease and the best way to protect against it.

As of 4 April the Guinean ministry of health had reported a total of 143 cases of the virus, of which 54 had been confirmed by laboratory tests. This number included 86 deaths.

The outbreak began in the rural area of Guekedou, where WHO reported the first cases on 23 March. This area has seen the most cases-85, including 59 deaths. Cases have also been seen in the neighbouring areas of Macenta and Kissidougou.

The outbreak spread to the capital, Conakry—some 400 miles from the initial outbreak-where there have been 18 cases, including five deaths. Fourteen cases of the disease have occurred among health workers, including eight deaths.

Liberia has also reported 18 suspected and two confirmed cases of the Ebola virus, including seven deaths, since 24 March.

The response to the disease is being coordinated by WHO with the Guinean ministry of health. WHO has doubled the number of its staff in Guinea from 30 to 60 .

A WHO spokesman in the country said, "This is the first time that there has been an outbreak of Ebola in Guinea, so there is a lot that staff don't know. We're trying to get more people in, as there is a need for more people with experience of the disease."

Concern had arisen that the cases reported in the Guinean capital were part of a separate outbreak, ${ }^{1}$ but the WHO spokesman confirmed that the cases were linked. "We know that it's one source and that the transmission was from human to human," he said.

Neither WHO nor MSF would speculate on the future trajectory of the disease.

In Africa fruit bats are believed to be the natural hosts of the virus, which is transmitted to humans through contact with infected bats or through hosts such as monkeys, apes, or pigs. The virus is passed from person to person through direct contact with the blood, secretions, or other bodily fluids. The only treatment available is symptomatic.

Ben Neuman, a virologist at the University of Reading in the United Kingdom, said that as a bloodborne infection the Ebola virus did not spread easily between people.

"However, until we understand more about why the Ebola virus grows in some cells and not in others, it is difficult to predict how difficult it would be for the virus to change the way it spreads," he said.

1 Gulland A. Ebola outbreak claims more than 60 lives. BMJ 2014;348:g2473.

Cite this as: BMJ 2014;348:g2644

(๑) BMJ Publishing Group Ltd 2014 